\title{
Kronik Otitis Media da Kulak Zarı Perforasyonları ve Kemik Zincir Patolojilerinin İşitme Kayıpları ile İlişsisi
}

\section{Relationship Between Hearing Losses of Tympanic Membran Perforations and Bony Chain Pathhologies in Chronic Otitis Media}

\author{
Zeki SEZGíN ${ }^{1}$, Mehmet KÜLEKÇí ${ }^{2}$ \\ ${ }^{1}$ Kulak burun boğaz ve Baş Boyun cerrahisi kliniği, Medical Park Hastanesi, Tokat, TÜRKIYE \\ 2 Kulak Burun Boğaz ve baş Boyun cerrahisi AD, Taksim Eğitim ve Araştırma Hastanesi, İstanbul, TÜRKIYE
}

\section{ÖZET}

Kronik otitis media(KOM), kulak zarında perforasyon, dış kulak yolundan zaman zaman kesilen süpüratif karakterde akıntı, çoğunlukla iletim tipinde olan bir işitme kaybı ve üç aydan fazla süreli medikal tedaviye cevap vermeyen otitis media türü olarak tanımlanabilir. Bu çalışmada 1999 Ocak - 1999 Aralık aylan arasında kliniğimizde kronik otitis media nedeniyle yatıp opere edilmiş 112 hastanın mevcut olan orta kulak patolojilerini ve bunlarla işitme kaybı arasındaki ilişkileri araştırıldı. Hastalarımız kolesteatomlu ve kolesteatomsuz olarak iki ayrı sınıfda incelendi. Timpanik membran patolojileri santral, attik, total, marjinal perforasyonlar, retraksiyon ve intakt kulak zarı olarak sınıflandırıldı. Kemikçik durumu fonksiyonel, kalıntı halinde, kemikçik yokluğu, hareketi kısıtlı ve hareketi fixe olarak sınıflandırıldı. Odyolojik tetkikleri yapıldı. Saf ses işitme eşikleri tespit edildi. Timpanik membran ve kemikçik zincir patolojilerinin işitme fonksiyonu üzerine etkileri incelendi.

Anahtar Kelimeler: Kronik otitis media, işitme kaybı, kulak zarı peforasyonu, kemikçik zincir

\section{ABSTRACT}

Chronic otitis media which is identifed by tympanic membran perforation, suppurative ear discharge from the external ear canal, usually conductive type hearing loss, for more than three months ve resistant to medical treatment is an otitis media type. In this study we investigated relationship between middle ear pathologies and hearing loss in 112 patients operated due to chronic otitis media between 1999 january and 1999 december in our clinic. Our patients were classified in two different groups as cholesteatomatous and non-cholesteatomatous chronic otitis media. Tympanic membran pathologies are classified as central, attic, total perforations, retraction and intact tympanic membran. Ossicles are classified as functional, destructed, no hearing bony structures and ossicular movement limited or fixed. Audiological tests were performed. Pure tone hearing treshould were determined.Effects about the hearing function of tympanic membran and ossiculer chaine pathologies are investigated.

Key words: Chronic otis media, hearing loss, tympanic membran perforation, ossicles
Corresponding Author: Zeki SEZGiN

Address: Tokat Medical Park Hastanesi Kulak Burun Boğaz ve baş boyun Cerrahisi Kliniği Tokat/TÜRKiYE

E-mail:sezginz@yahoo.com.tr
Başvuru Tarihi/Received: 21-09-2016

Kabul Tarihi/Accepted: 11-10-2016 


\section{GíRiş}

Kronik otitis media,kulak zarı ve orta kulak boşluklarının mukoza ve kemik yapılarının uzun süreli enflamasyonuna kronik otitis media denir1. Altı haftadan uzun süren otitlerde kronik otitis media'dan söz edilir. Günümüzde travmatik olgular göz önünde tutulmazsa genellikle kronik otitis medialar akut süpüratif otitis media'nm sekeli olarak kabul edilmektedir2.

Kronik otitis mediaların belli başlı üç karakteri vardır. Bunlar; timpanik membran perforasyonu, dış kulak yolunda zaman zaman kesilen süpüratif karakterde akıntı ve çoğunlukla iletim tipinde olan bir işitme kaybıdır. İşitme kaybının derecesi perforasyonun büyüklüğüne ve lokalizasyonuna bağlıdır $(3,4)$.

KOM'a sıklıkla benign bir tümör olan kolesteatom eşlik eder. Bu orta kulak tümörü,keratin debrislerin akümülasyonuyla karakterizedir ve lokal kemik rezorpsiyonuna yol açabilir(5,6)

$K O M^{\prime}$ da görülen kemik erimesi ile ilgili birçok mekanizma bildirilmiştir. Bumekanizmalar; kronik osteomiyelit, osteoklastik osteolizis, basınç nekrozu, osteositik osteolizis, monosit aracılığı ile erime, kollejenaz, asit fosfataz ve lizozim gibi enzimleraracılığı ile erime, lokal $\mathrm{Ph}$ değişiklikleri ve vaskuler proliferasyondur $(7,8)$.

Bu faktörler ayrı ayrı ya da kombine halde kemik erimesine sebep olabilir.

Kronik otitis medialı hastalar lokal sorunları yanında komplikasyon bulgulan ile de halen K.B.B. kliniklerine gelen hastalarının çoğunluğunu oluşturmaktadır. Bu hastalara komplikasyon olsun veya olmasın genellikle cerrahi bir girişim gerekli olmaktadır.

Kronik otitis medialı bir hastaya yapılacak cerrahi girişimlerde patoloji ortadan kaldınımaya çalışılırken var olan işitme kaybının nasıl düzeltilebileceği de planlanmalıdır. $\mathrm{Bu}$ nedenle hastalann preoperatif işitme seviyelerinin bilinmesi bilinmesi zorunludur. Bu zorunluluk sadece medikal değildir. Hastalann çoğu operasyon sonrasındaki başarıyı işitme seviyesindeki düzelme ile değerlendirmektedir. Otitis media ilişkili işitme kaybı çoçukların dil becerilerini, sosyal gelişimini ve eğitim başarılarını tehlikeye atabilir(9). Bu yüzden hastaların bu konuda preoperatif olarak bilgilendirilmeleri önemlidir. Yapılacak ameliyat sonrasında hastadaki muhtemel işitme seviyesinin ne olabileceği hastalara anlatılmalıdır.

\section{MATERYAL VE METOD}

Bu çalışma SSK İstanbul Eğitim Hastanesi KBB Kliniğinde 1999 Ocak- 1999 Aralık tarihleri arasında kronik otitis media tanısı ile ameliyat edilen 112 hastanın orta kulak patolojilerinin pre ve peroperatuar olarak incelenmesini ve bu patolojilerle işitme kaybı arasındaki ilişkiyi içermektedir.

Olgularımız kliniğimize ameliyat edilmek üzere yattığı andan itibaren prospektif olarak incelemeye alındı. Hastalarımızın tamamına preoperatif olarak mikroskop muayenesi yapılmış olup; dış kulak yolu durumu, akıntının varlığı ve karakteri, perforasyon şekilleri ve lokalizasyonu, orta kulak mukozasının durumu, polip, granülasyon dokusu veya kolesteatom varlığı, orta kulakta veya zar bakiyesinde skleroz bulunup bulunmadığı, görülebiliyorsa kemik zincir durumu kodlanarak tespit edilmiştir.

Hastalann pür ton odyogramlan kliniğimiz odyoloji ünitesinde yapılarak tespit edilmiştir. Olguların peroperatif bulgulan; kemik zincir durumu, polip, granülasyon, fîbrozis ve kolesteatom varlığı ve lokalizasyonu, orta kulak mukozasının durumu incelenerek kodlanmıştır.

Timpanik membrandaki perforasyon ve patolojileri sınıflandınrken; perforasyon eğer anulusu geçmiş ve dış kulak yoluna açılmış ise marjinal perforasyon olarak adlandırdık. bakiyesi yoksa total perforasyon olarak kabul ettik. Pars tensada hangi kadranda olursa olsun zar bakiyesi varsa santral perforasyon 
olarak adlandırdık. Perforasyon pars tensadaki 4 kadranı içine almış, fakat bir miktar zar bakiyesi var ise subtotal santral perforasyon, hiç zar bakiyesi yoksa total perforasyon olarak kabul ettik. Pars tensada hangi kadranda olursa olsun zar bakiyesi varsa santral perforasyon olarak nitelendirdik. Fakat bu perforasyonlan da kendi aralarında kadranlara göre sınıflandırdık. Timpanik membranda retraksiyon olarak nitelendirdiğimiz olgularımız; zarın tamamı veya posterior kadranlarının kemik zincire veya promontoriuma yapışmış olduğu ve kendi kendini temizleyemediği, bir kısmında akıntının olduğu ve retraksiyon poşunun attiğin altına doğru uzanıp apeksinin gözükmediği, bir kısmında da granülasyonlann geliştiği kronik otit olgulan idi.

Kemikçikler fonksiyona sahip iseler (tam ve hareketli), hafif össeöz değişime uğramış olsalar bile 'fonksiyona sahip' olarak belirtilmişlerdir. Kemikçiklerde kemik zincirde kopukluğa neden olacak kadar erezyon saptanmışsa 'kalıntı halinde' olarak belirtilmiştir. Stapes suprastrüktürünün total olarak yok olduğu ve sadece stapes tabanının mevcut olduğu olgulan da kemikçik yokluğu olarak değerlendirmeye aldık.

Ortalama işitme kaybı oranı hastalara yapılan preoperatuar odyogramlann 500, 1000, $2000 \mathrm{~Hz}$ frekanslarındaki kayıp oranının ortalaması bulunarak tespit edilmiştir. Orta kulaktaki iletim patolojisi ve işitme kaybı arasındaki ilişki incelenirken hava ve kemik yolu işitme eşiği arasındaki gap oranı ve hava yolu işitme eşiği göz önüne alınmıştır.

Olgularımız preop veya peroperatif olarak saptadığımı kolesteatom patolojisine göre kolesteatomlu ve kolestatomsuz kronik otitis media olarak ayrı ayrı iki grup olarak incelenmiş ve sonuçlar birbiriyle karşılaştınImıştır.

\section{BULGULAR}

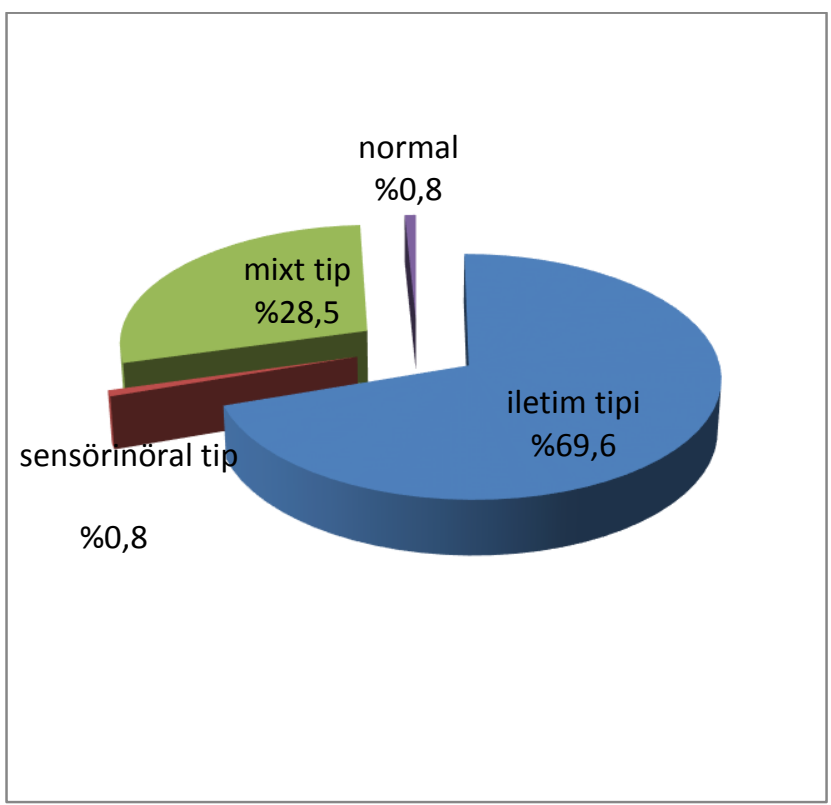

Şekil 1. Hastalarımızın işitme kaybı tiplerinin dağılımı.

Kronik otitis media nedeniyle opere edilen 112 hasta incelendi. Şekil 1 de görüldüğü gibi kolesteatomsuz ( 55 olgu ) ve kolesteatomlu (23 olgu) tüm kronik otitis medialarda \% 69.6 oranla en fazla görülen işitme kaybı iletim tipindedir. Bunu \% 28.5 ile mikst tip işitme kaybı(32 olgu) ve \% 0.8 ile sensorinöral işitme kaybı(1 olgu) takip etmektedir. 1 olgu da ise normal işitme seviyesi mevcuttu.

Perforasyon şekillerinin dağılımına baktığımızda ise Grafik 1 de görüldüğü gibi kolesteatomlu ve kolestetomsuz kronik otitis medialı bütün olgularımızda ki perforasyonlarda \% 64.2' lik büyük bir oranla santral perforasyon ilk sırayı almaktadır. Kolesteatomlu kronik otitis medialarda ki perforasyonlar da ise \% 33.3lük bir oranla attik perforasyonlan ilk sırayı almaktadır. 


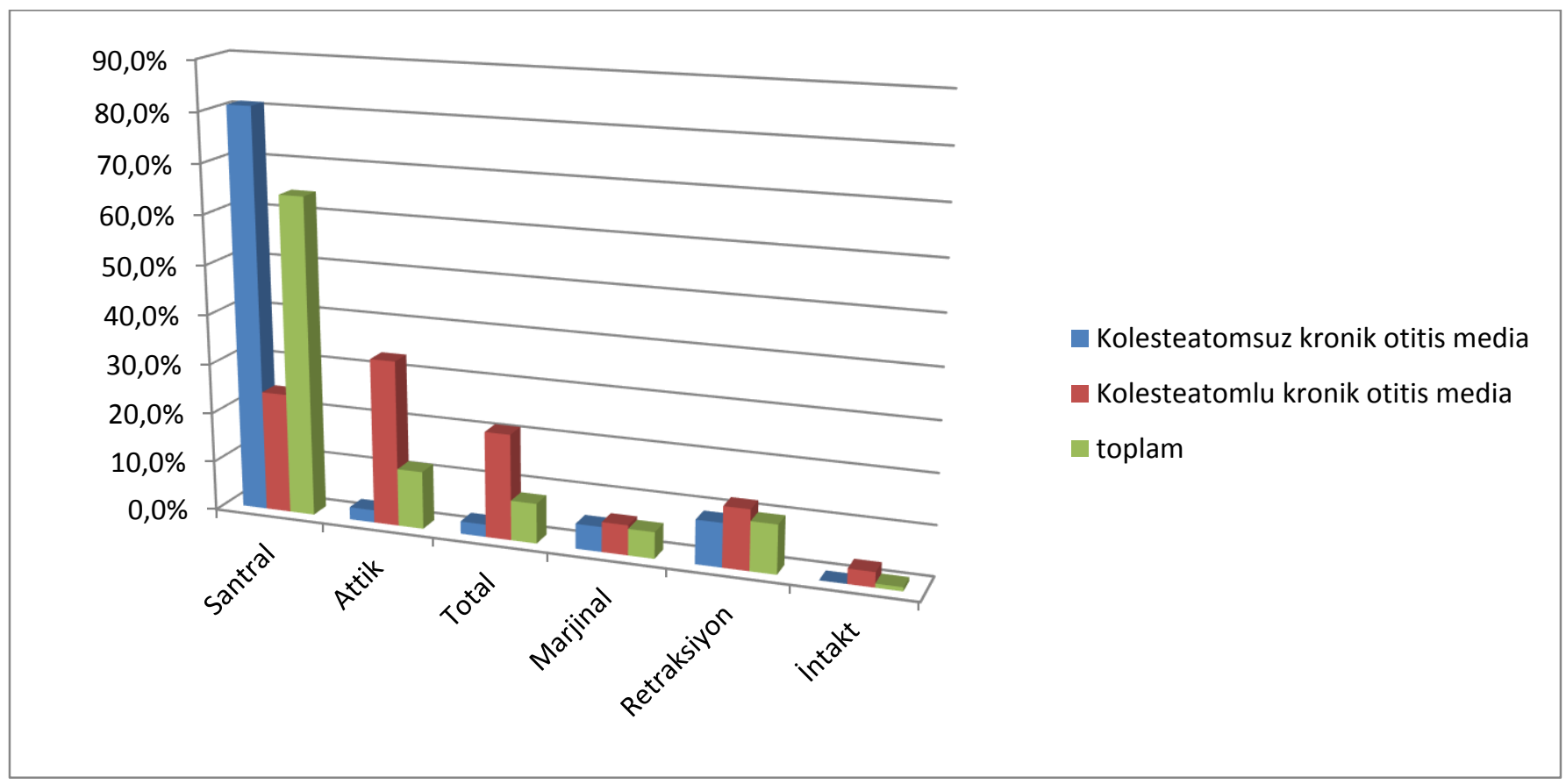

Grafik 1. Kronik otitis mediada perforasyon şekillerinin dağılımı

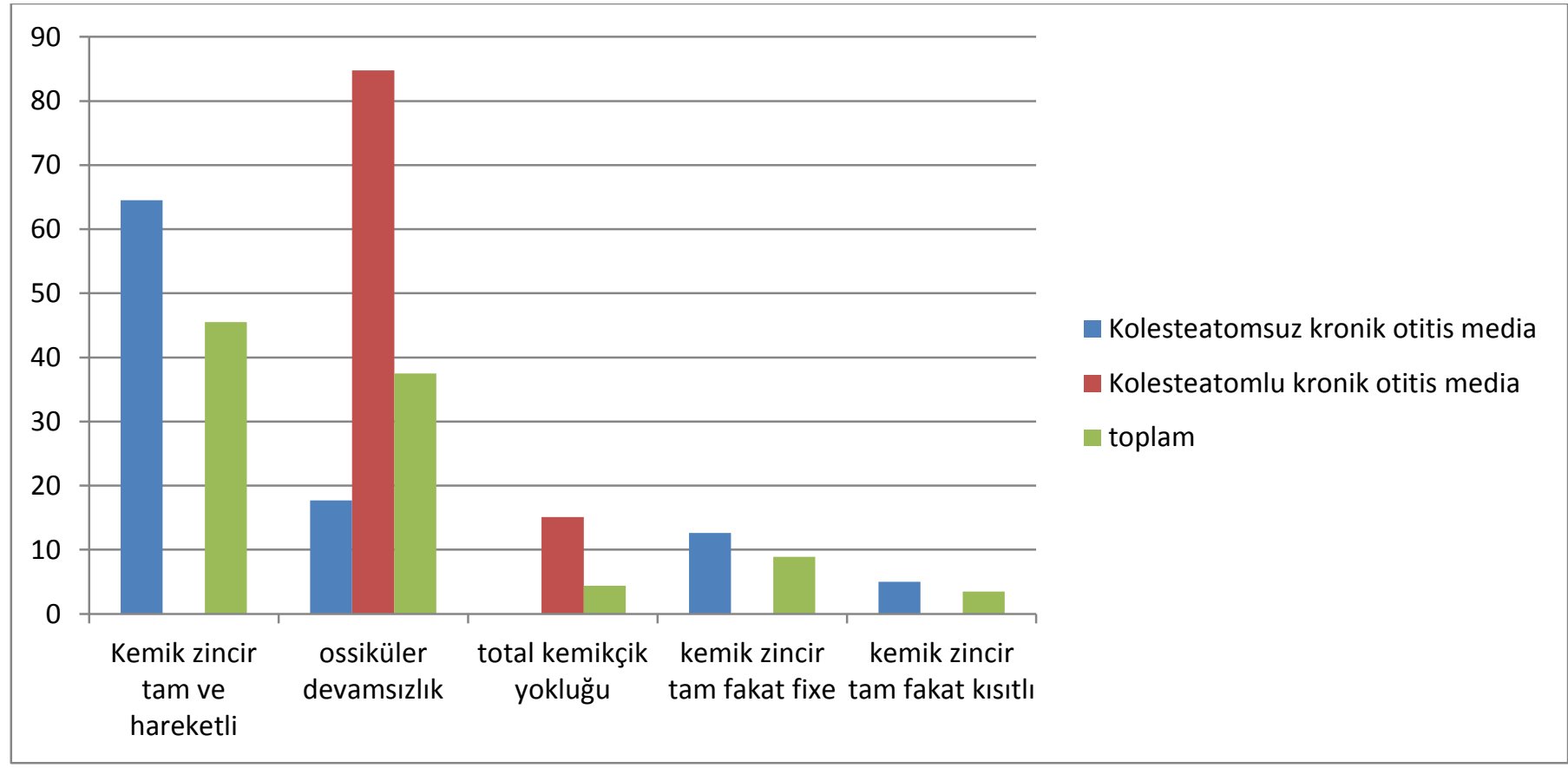

Grafik 2. Kronik otitis medialı hastalarımızın kemik zincir patolojileri dağılımı

Grafik 2'de görüldüğü gibi olgularımızın tamamının \% 45.5'inde peroperatif olarak kemikçikler tam ve hareketli olarak saptandı. Kolesteatomlu kronik otitlerin ise tamamında kemik zincir bütünlüğü bozulmuştu. \% 84.8'inde ossiküler devamsızlık, \%15.1'inde ise total kemikçik yokluğu mevcuttu. Kolesteatomsuz kronik otitlerde ise total kemikçik yokluğu gözlenmedi. 


\begin{tabular}{|c|c|c|c|c|c|c|c|c|c|c|}
\hline & & \multicolumn{3}{|c|}{ MALLEUS } & \multicolumn{3}{|c|}{ INKUS } & \multicolumn{3}{|c|}{ STAPES } \\
\hline \multicolumn{2}{|l|}{$\begin{array}{l}\text { KEMIKçіK } \\
\text { DURUMU }\end{array}$} & $\begin{array}{c}\text { Kolesteatomsuz } \\
\text { KOM }\end{array}$ & $\begin{array}{c}\text { Kolesteatomlu } \\
\text { KOM }\end{array}$ & Toplam & $\begin{array}{c}\text { Kolesteatomsuz } \\
\text { KOM }\end{array}$ & $\begin{array}{c}\text { Kolesteatomlu } \\
\text { KOM }\end{array}$ & Toplam & $\begin{array}{c}\text { Kolesteatomsuz } \\
\text { KOM }\end{array}$ & $\begin{array}{c}\text { Kolesteatomlu } \\
\text { KOM }\end{array}$ & Toplam \\
\hline \multirow{2}{*}{ Fonksiyonel } & $\mathrm{N}=$ & 57 & 21 & 78 & 50 & 2 & 52 & 57 & 12 & 69 \\
\hline & $\%$ & 72.1 & 63 & 69 & 63.2 & 6 & 46.4 & 72.1 & 36 & 61 \\
\hline \multirow{2}{*}{ Kalıntı halinde } & $\mathrm{N}=$ & 4 & 10 & 14 & 12 & 21 & 33 & 2 & 3 & 5 \\
\hline & $\%$ & 5 & 30 & 12 & 15.1 & 63 & 29.4 & 2,5 & 9 & 4.4 \\
\hline \multirow{2}{*}{$\begin{array}{l}\text { Kemikçik } \\
\text { yokluğu }\end{array}$} & $\mathrm{N}=$ & 1 & 2 & 3 & 1 & 10 & 11 & 5 & 18 & 23 \\
\hline & $\%$ & 1.2 & 6 & 2.6 & 1.2 & 30 & 9.8 & 6.3 & 54 & 20 \\
\hline \multirow{2}{*}{ Hareketi kısıtlı } & $\mathrm{N}=$ & 8 & 0 & 8 & 8 & 0 & 8 & 6 & 0 & 6 \\
\hline & $\%$ & 10.1 & 0 & 7.1 & 10.1 & 0 & 7.1 & 7.5 & 0 & 5.3 \\
\hline \multirow{2}{*}{ Hareketi fixe } & $\mathrm{N}=$ & 9 & 0 & 9 & 8 & 0 & 8 & 9 & 0 & 9 \\
\hline & $\%$ & 11.3 & 0 & 8 & 10.1 & 0 & 7.1 & 11.3 & 0 & 8 \\
\hline
\end{tabular}

Tablo 1. Kronik otitis medialı hastalarımızda kemikçikler ile kemik zincir patolojileri arasındaki ilişki

Tablo 1'de görüldüğü gibi kolesteatomsuz kronik otitis meda'da en fazla fonksiyonel (tam ve hareketli) kemikçik \% 72.1 ile eşit oranda malleus ve stapes peroperatif olarak saptanmıştır.

Kolesteatomlu kronik otitis media'lı olgularımı da ise yine en fazla fonksiyona sahip kemikçik \% 63.6' lık oranla malleus görülmüştür. Bunu \% 36.3 ile stapes ve en az fonksiyona sahip $\% 6^{\prime}$ lık oranla inkus takip etmektedir.

Kolesteatomlu kronik otitis media'lı olgularımı da ise yine en fazla fonksiyona sahip kemikçik \% 63.6' lık oranla malleus görülmüştür. Bunu \% 36.3 ile stapes ve en az fonksiyona sahip $\% 6^{\prime}$ lık oranla inkus takip etmektedir.

Kemikçik yokluğu; kolesteatomsuz K.O.M'.larda \% 6.3, kolesteatomlu K.O.M' da \% 54.3 ile en fazla stapes de görülmüştür.

Kolesteatomlu kronik otitler de inkus daha fazla olarak ( \%63.6 ) kalıntı halinde gözükürken, stapes daha fazla olarak ( \%54.5) kemikçik yokluğu olarak karşımıza çıkmaktadır. İnkusun erezyona uğradığı olguların \% $38.2^{\prime}$ inde inkusun uzun kolu erode idi. \% 34 'ünde inkus kalıntı (uzun ve kısa kolu erode) halinde, \% 23.4'ünde inkus yoktu. \% 4.2'sinde ise inkusun sadece kısa kolu erode idi.

Timpanik membran ve kemik zincir patolojileri ile işitme kaybı arsındaki ilişkiye baktı̆ı̆ızda;
Kemik zincirin tam ve hareketli olup; timpanik membranda perforasyon bulunan olgularda işitme seviyesi:

Olgu Sayısı: 51

Ortalama air-bone gap : $26.9 \mathrm{~dB}$

Ortalama hava yolu iletim eşiği: 38.9 dB

Kemik zincirin tam, fakat hareketinin kısıtlı veya fikse olup; timpanik membranda perforasyon bulunan olgularda işitme seviyesi: Olgu sayısı: 14

Ortalama air-bone gap: $30.9 \mathrm{~dB}$

Ortalama hava yolu iletim eşiği: $52.9 \mathrm{~dB}$

Kemik zincirde kopukluk olan kolesteatomsuz KOM' larda işitme seviyesi: Olgu sayısı: 14

Ortalama air-bone gap: $31.2 \mathrm{~dB}$

Ortalama hava yolu iletim eşiği: 49.9 dB

Ön kadran timpanik membran perforasyonların da işitme seviyesi: (Kemik zincir tam ve hareketli )

Olgu sayısı: 11

Ortalama air-bone gap: $19 \mathrm{~dB}$

Ortalama hava yolu iletim eşiği: $31.2 \mathrm{~dB}$

Alt kadranları tutan timpanik membran perforasyonların da işitme seviyesi: (Kemik zincir tam ve hareketli)

Olgu sayısı: 12

Ortalama air-bone gap: $24.2 \mathrm{~dB}$

Ortalama hava yolu iletim eşiği: $40.5 \mathrm{~dB}$

Posterior kadranlarda perforasyonu bulunan (Marjinal perforasyonlar dahil) kolesteatomsuz K.O.M.'da işitme seviyesi: 
Olgu sayısı: 10

Ortalama air-bone gap: $26.2 \mathrm{~dB}$

Ortalama hava yolu işitme eşiği: $39.4 \mathrm{~dB}$

Posterior kadranlarda perforasyonu

bulunan (Marjinal perforasyonlar dahil) Kolesteatomlu K.O.M' da işitme seviyesi:

Olgu sayısı: 6

Ortalama air-bone gap: $32.6 \mathrm{~dB}$

Ortalama hava yolu işitme eşiği: $48.5 \mathrm{~dB}$

Geniş santral perforasyonu (Subtotal veya böbrek tarzı) bulunan olgularda işitme seviyesi: (Kemik zincir tam ve hareketli) Olgu sayısı: 14

Ortalama air-bone gap: $31.7 \mathrm{~dB}$

Ortalama hava yolu iletim eşiği: $42.3 \mathrm{~dB}$

Total perforasyonu bulunan olgularda

işitme seviyesi: (Kemik zincir tam ve hareketli)

Olgu sayısı: 2

Ortalama air bone gap: $32 \mathrm{~dB}$

Ortalama hava yolu iletim eşiği: $52.5 \mathrm{~dB}$

Total perforasyonu bulunan kolesteatomlu KOM' da işitme seviyesi: Olgu sayısı: 7

Ortalama air-bone gap: $37.5 \mathrm{~dB}$

Ortalama hava yolu işitme eşiği: $62 \mathrm{~dB}$

Subtotal perforasyonu bulunan ve kemik zincirin tam fakat hareketinin kısıtlı veya fikse olduğu olgularda işitme seviyesi:

Olgu Sayısı: 5

Ortalama air-bone gap: $33 \mathrm{~dB}$

Ortalama hava yolu iletim eşiği: $57.6 \mathrm{~dB}$

Timpanik membranda retraksiyon patolojisinin bulunduğu kolesteatomsuz $\mathrm{KOM}^{\prime}$ da işitme seviyesi:

Olgu Sayısı: 6

Ortalama air-bone gap: $23.1 \mathrm{~dB}$

Ortalama hava yolu iletim eşiği: $37.8 \mathrm{~dB}$

Timpanik membranda retraksiyon patolojisinin bulunduğu kolesteatomlu KOM' da işitme seviyesi:

Olgu Sayısı: 5

Ortalama air-bone gap: $26.2 \mathrm{~dB}$

Ortalama hava yolu iletim eşiği: $42.8 \mathrm{~dB}$

Kolesteatomsuz tüm KOM' da işitme seviyesi:
Olgu sayısı: 79

Ortalama air-bone gap: $28 \mathrm{~dB}$

Ortalama hava yolu iletim eşiği: $43.4 \mathrm{~dB}$

Kolesteatomlu tüm KOM' larda işitme seviyesi:

Olgu sayısı: 33

Ortalama air-bone gap: $32.9 \mathrm{~dB}$

Ortalama hava yolu iletim eşiği: $49 \mathrm{~dB}$

Attik perforasyonu bulunan olgularda işitme seviyesi:

Olgu sayısı: 13

Ortalama air-bone gap: $31.6 \mathrm{~dB}$

Ortalama hava yolu iletim eşiği: $41.6 \mathrm{~dB}$

Ossiküler devamsızlık bulunan Kolesteatomlu KOM' da işitme seviyesi:

Olgu sayısı. 28

Ortalama air-bone gap: $32 \mathrm{~dB}$

Ortalama hava yolu iletim eşiği: $43.6 \mathrm{~dB}$

Total ossiküler yokluğun bulunduğu Kolesteatomlu KOM' da işitme seviyesi:

Olgu sayısı: 5

Ortalama air-bone gap: $36.6 \mathrm{~dB}$

Ortalama hava yolu iletim eşiği: $60.4 \mathrm{~dB}$

Ossiküler devamsızlık bulunan fakat stapesin tam olduğu Kolesteatomlu KOM' da işitme seviyesi:

Olgu sayısı: 13

Ortalama air-bone gap: $26.3 \mathrm{~dB}$

Ortalama hava yolu iletim eşiği: $40.2 \mathrm{~dB}$

\section{TARTIŞMA}

Kronik otitis media orta kulak boşluklarında irreversibl iltihabi değişikliklerin oluşumu ile karakterizedir.10 Hastalık devam eden süpürasyonla birlikte aktif veya geçirilmiş enfeksiyondan kalmış sekellerle birlikte inaktif şekillerde bulunabilir.

Kronik otitis medianm bulguları genelde granülasyon dokusu, kolesteatom, kolesterol granülom, kemik değişiklikleri, timpanoskleroz, fibrozis,glandüler formasyon ve epitelyal metaplazi şeklinde özetlenebilir.11 
Schuknecht'e göre, kronik otitis mediadaki önemli bulgular; mukoza ödemi, ülserasyon, polip ve granülasyon dokusu teşekkülü, kemikçiklerde, labirent kapsülünde ve mastoid kemikte yıkıcı (rarefaction) osteit, keraton teşekkülü, epidermizasyon, fıbrozis, fibrosistik ve fıbroossöz skleroz ve timpanosklerozdur .12

Friedman'a göre süpüratif kronik otitis mediada primer patolojik proçes olguların \% 49 'unda granülasyon, $\% 25^{\prime}$ inde ise kolesteatom veya kolesterin granülomudur. 13

Paperella, kronik otitis medianın gelişiminde ve prezantasyonunda Friedman gibi granülasyon dokusunu kolesteatomdan daha etkin bulmuştur .14

Çalışmamıza giren 112 olgunun 32 'sinde (\%28.5) granülasyon dokusu, 33'ünde de (\%29.5) kolesteatom ile karşılaşıldı. Kolesteatom sıklığı Friedman'ın bildirdiği \% 25 lik orana yakın bulundu.

Kronik otitis mediadaki işitme kayıplan iletim tipinde, mixt tipte ve bazen de sensorinöral tipte işitme kaybı şeklinde olabilir.

Çalışmamıza giren 112 olgunun işitme kaybı şekillerini gösteren şekil l'de iletim tipi işitme kaybı \% 69.6, mixt tip işitme kaybı \% 28.5 ve kolesteatomlu kronik otitli 1 olguda ( $\%$ 0.8) pür sensorinöral işitme kaybı bulunmuştur.

Paparella'ya göre kronik otitlerin \% 43'ünde $15 \mathrm{~dB}$ 'in üstünde, \% 16'sında ise 30 $d^{\prime}$ 'in üstünde sensorinöral işitme kaybı bulunur.15

Bizim çalışmamıza göre olgularımızın \% $38.3^{\prime}$ de $15 \mathrm{~dB}$ 'den, \% 7'sinde ise $30 \mathrm{~dB}$ 'den daha fazla sensorinöral komponenti bulunan işitme kaybı tespit edilmiştir.

Yapılan çalışmalar timpanik membran ve orta kulak patolojileri arasında miringoskleroz ve granülasyon dokusu, miringoskleroz ve ossiküler patoloji, perforasyon ve ossiküler patoloji, hemoraji ve ossiküler patoloji şeklinde belirgin bir ilişki olduğunu göstermiştir.16

Zardaki perforasyon ses iletimini olumsuz yönde etkiler. Perforasyon yüzünden titreşen kulak zan yüz ölçümü küçülür, orta kulağın amplifikatör etkisini yapan kulak zan ve oval pencere yüz ölçümleri arasındaki oran küçülür ve bu da işitmenin azalmasına yol açar.1

Perforasyonun yeri ve büyüklüğü işitme üzerinde etkili ikinci önemli faktördür. Perforasyon ne kadar büyükse işitme kaybı da o kadar fazla olur.3

Pars flaksidayı tutan perforasyonlar işitmeyi önemli ölçüde etkilemezler. Arka kadrandaki perforasyonlar ise işitmeyi önemli derecede etkiler. Çünkü maksimum amplitüd içinde bulunurlar. Eğer yuvarlak pencere karşısında iseler kulak zarının pencereleri koruma etkiside ortadan kalkar. İşitme üzerine etkisi en fazla olan total perforasyonlardır.

Çalışmamıza giren 112 olgunun timpanik membran patolojileri (perforasyon, retraksiyon) Grafik 1'de gösterilmiştir.

$\begin{array}{rlr}\text { Kronik } & \text { otitis medianm önemli } \\ \text { bulgularından } & \text { biride } & \text { kemikçiklerdeki }\end{array}$ erezyondur. Kuşkusuz osseöz değişiklikler orta kulak duvarlarının bütününde görülebilir. Ancak kemikçiklerdeki erezyon ses iletimini etkiler ve işitmeyi düşürür. Dolayısıyla rekonstrüktif işlemlerde kemikçiklerin durumu önemli bir faktör teşkil eder.10, 17

Kemikçiklerde erezyon yanmda fıksasyon da görülebilir. Ameliyat sırasında fiksasyonun farkına varılamazsa rekonstrüktif cerrahide başarı sağlanamaz.18

Kemik erezyonlan kolesteatomla eşleştirilmiştir. Ancak yapılan histolojik çalışmalar erezyonun oluşmasmda kolesteatomun direkt etkisinin yanmda inflamatuar proçesin daha büyük oranda rol oynadığını göstermiştir.17,19 Kemik rezorbsiyonu ve tahribatı baskıya (kolesteatomda olduğu gibi) ve anoksiye bağlandığı gibi daha yeni araştırmalar vaskülarizasyonun artmasının, enzimlerin, sellüler aktivitenin (histiosit, osteoklast, osteoblast gibi) ve prostoglandinlerin bu konuda çok daha önemli rol oynayabileceklerini ortaya çıkarmıştır.20 
Kemikçiklerden inkus ve stapes ayrıldığı zaman meydana gelen işitme kaybı 50 $\mathrm{dB}$ dolayındadır.Eğer inkus ve malleus çıkarılırsa bu kayıp 40 dB' e iner. Yani 40 dB'in üzerindeki kayıplar için kemikçik zincirinde devamsızlık olduğu kanaatine varabiliriz. Ancak bu her zaman için geçerli değildir. Çünkü kemikçik zincirinde kopma olsa bile fibröz bağlar, polipler ve kolesteatom kitleleri iletimde rol oynayabilir ve işitme kaybı olması gerekenden daha az olabilir. Kemikçik zincirdeki fiksasyon durumlarında işitme kaybı $40 \mathrm{~dB}$ 'in üzerinde olur.

Austin'in 1978 yılında geniş bir hasta grubunda kulak zan perforasyonlannm büyüklüklerinin işitmeye etkisini içeren araştırmasında ortalama \% 15 perforasyonlarda ortalama $11.6 \mathrm{~dB}$, ortalama $\% 40$ perforasyonlarda ortalama $22 \mathrm{~dB}$ ve ortalama \% 65 ve daha geniş perforasyonlarda ortalama $28 \mathrm{~dB}^{\prime}$ lik bir işitme kaybı tesbit edimiştir.3

Kolesteatomsuz kronik otititis medialı ve kemik zincirin tam ve hareketli olduğu ve Austin'in \% 40 lık perforasyonuna uyan ön kadranlan tutan perforasyonu olan olgularımızda ( \% 9.8 ) ortalama air-bone gap $19 \mathrm{~dB}$, alt kadranlan tutan perforasyonu olan olgularımızda ise (\% 10.7) ortalama $24.2 \mathrm{~dB}$ iletim tipi işitme kaybı saptanmıştır. Bu iki perforasyon şeklinin ortalaması 21,6 dB' dir ve Austin'in ortalama \% 40 perforasyonlarda saptadığı ortalama $22 \mathrm{~dB}$ lik işitme kaybı ile uyumludur.

Kemik zincirin tam ve hareketli olduğu ve Austin'in \% 65 ve daha geniş perforasyonuna uyan geniş santral perforasyonu olan ( subtotal veya böbrek tarzı perforasyonlar) olgularımızda (\%12.5) ortalama işitme kaybımız $31.7 \mathrm{~dB}$ olarak tespit edilmiştir. Austin'in saptadığı $28 \mathrm{~dB}$ 'lik işitme kaybma yakındır.

Timpanik membrandaki perforasyonun lokalizasyonuna göre olgularımızdaki işitme kayıplarına baktığımızda en az işitme kaybı ön kadranlan (anterior superior ve anterior inferior kadranlar) tutan perforasyonlarda bulunmuştur. Olgularımızın \% 9.8 'ini oluşturan bu tip perforasyonlardaki ortalama işitme kaybı air-bone gap olarak $19 \mathrm{~dB}$ bulunmuştur. Kemik zincirin tam ve hareketli olduğu alt kadranları tutan perforasyonlar olgularımızın \% 10.7'sinde mevcuttur. Bunların ortalama işitme kaybı oranı $24.2 \mathrm{~dB}^{\prime}$ dir.

Kolesteatomsuz, kemik zincir tam ve hareketli, sadece timpanik membran perforasyonu olan (perforasyon lokalizasyonuna bakılmaksızın) olgularımızda (\% 45.5) ortalama işitme kaybı oranı $26.9 \mathrm{~dB}$ olarak bulunmuştur.

Total perforasyonlu olgularda ise ise işitme eşiği 32 dB'e kadar düşmüştür. Bu bulgular bize perforasyonun büyüklüğünün işitme üzerinde etkili olduğunu ve perforasyonun büyüklüğü arttıkça işitmenin daha da kötüleşeceğini göstermektedir.

Olguların \%11.6 'ında attikte perforasyon mevcuttu. Bu gruptaki ortalama işitme kaybı oranı $31.6 \mathrm{~dB}$ olarak bulunmuştur. Attik perforasyonlanndaki işitme kaybımn yüksek bulunmasının sebebi olgularımızdaki bu tip perforasyonlu kulakların büyük kısmında kemikçik zincirinin normal fonksiyona sahip olmaması gösterilebilir.

Orta kulak timpanoskleroz olgularında ciddi iletim tipi işitme kayıplan vardır.İşitme kaybı genellikle $60 \mathrm{~dB}$ civarındadır ve kemikçiklerin fiksasyonuna bağlıdır. Yapılan çalışmalar timpanosklerozun kemik iletim eşiğini kötüleştirdiği ve mixt tip işitme kaybma yol açtığı gösterilmiştir.21,22

Olgularımızın \% 12.5'unda kemik zinciri tam, fakat hareketleri kısıtlı veya fixxe (timpanoskleroz) durumda idi. Bu tip olgularda perforasyonu bulunan hastalarda ortalama airbone gap $30.9 \mathrm{~dB}$ olarak saptanmıştır Araştırmamıza giren 112 hastanın 11'inde (\% 9.8) timpanik membranda ileri derecede retraksiyon saptanmıştır.

Araştırmamıza giren 112 hastanın 11 'inde (\%9.8) timpanik membranda ileri derecede retraksiyon saptanmıştır.

Genellikle adheziv otit sonucu gelişen işitme kaybı; yapılan çalışmalarda 40-50 dB 
civarında iletim tipi bir işitme kaybıdır. Hastalığın ileri evrelerinde, tiz seslerde kemik yolu düşmesi ile karakterize mixt tip işitme kayıplanna rastlanır. Kemikçik zincirinde, özellikle inkusun uzun kolunda erime ile birlikte olan olgularda bile işitme kaybı çok fazla olmaz. Bunun sebebi, kulak zannın doğrudan stapes başma yapışması ve iletimin bu yolla sağlanmasıdır. Ancak kolesteatomla birlikte olan olgularda, aktif kemik erimesi ile işitme kaybı artabilir.1

Kulak zarında retraksiyon saptanan kolesteatomsuz kronik otitlerde ortalama işitme kaybı, air-bone gap olarak $23.1 \mathrm{~dB}$, hava yolu iletim eşiği olarak $37.8 \mathrm{~dB}$ saptanmıştır. Kolesteatomlu kronik otitlerde ise ortalama işitme kaybı; air-bone gap olarak $26.2 \mathrm{~dB}$, hava yolu iletim eşiği olarak $42.8 \mathrm{~dB}$ bulumuştur. Olgularımızda kulak zarında ileri derecede retraksiyon saptanan kolesteatomlu kronik otitlerdeki işitme kaybı, kulak zarında perforasyon bulunan kolesteatomlu kronik otitlerdeki işitme kaybından daha iyi bulunmuştur. Buda bize retrakte olan kulak zarının, kemik zincirde kopukluk olsa bile, stapes üzerine veya oval pencere üzerine yapışıp ses iletimini devam ettirmesine bağlanabilir.

Perforasyon ve kemik zincir kopukluğu bir arada ise aşağı yukarı işitme kaybı $38 \mathrm{~dB}$ civarındadır.

Total perforasyon ve kemikçik zinciri kopukluğu halinde ise işitme seviyesi $50 \mathrm{~dB}$ 'i bulmaktadır. İşitme kaybının artmasında geniş perforasyon sebebi ile faz koruma etkisinin ortadan kalkması en önemli etkendir. Perforasyon ve kemik zincir kopukluğu bulunan kolesteatomsuz kronik otitler çalışmamızda \% 12.5 oranında saptanmıştır. $\mathrm{Bu}$ gruptaki ortalama işitme kaybı $31.2 \mathrm{~dB}$ olarak bulunmuştur.

Total perforasyonu bulunan ve kemikçik zincirinde kopukluk bulunan kolesteatomlu kronik otitlerde ortalama airbone gap $37.5 \mathrm{~dB}$ olarak saptanmıştır. Hava yolu iletim eşiği ise $62 \mathrm{~dB}$ olarak bulunmuştur.
Perforasyon ve kemik zincir kopukluğu bulunan (ossiküler devamsızlık) kolesteatomlu kronik otitler çalışmamızda \%25 olarak saptanmıştır. Bu gruptaki ortalama işitme kaybı $32 \mathrm{~dB}$ olarak bulunmuştur. Perforasyon ve kemik zincirde devamsızlık olan olgularda kolesteatomsuz yada kolesteatomlu olması arasında fark bulunmamıştır.

Total ossiküler yokluğun bulunduğu kolesteatomlu kronik otitler çalışmamızda \% 4.4 oranında bulunmuştur. Ortalama air-bone gap $36.6 \mathrm{~dB}$ bulunmuştur. Hava yolu iletim eşiği ise $60.4 \mathrm{~dB}$ olarak saptanmıştır.

Ossiküler devamsızlık olan, fakat stapesin tam olduğu olgular araştırmamızda \% $11.6 \mathrm{~dB}$ oranında tespit edilmiştir. Bu grupta ortalama air-bone gap $26.3 \mathrm{~dB}$ gibi düşük oranda saptanmıştır. Hava yolu iletim eşiği ise 40.2 dB'dir. Kemik zincirde kopukluk olmasına rağmen bu grupta işitmenin daha iyi olması mevcut olan stapesin iletimi sağlaması ve faz farkını koruması gösterilebilir.

\section{SONUÇ}

SSK İstanbul Eğitim Hastanesi KBB Kliniğinde opere edilen 112 kronik otitis media'lı hastanın opere edilen kulaklarının pre ve peroperatuar klinik değerlendirilmesinden aşağıdaki sonuçlar ortaya çıkmaktadır.

1. Illetim tipi işitme kaybı \% 69.6' lık oranla en sık rastlanan işitme kaybı türüdür.

2. Zardaki perforasyonun şekline ve büyüklügüne göre en fazla işitme kaybı oranı $32 \mathrm{~dB}$ olarak total perforasyonlu kulaklarda görülmüştür.

3. En düşük işitme kaybı oranı $19 \mathrm{~dB}$ olarak ön kadranları tutan timpanik membran perforasyonlu kulaklarda bulunmuştur. Bu sonuç bize perforasyonun şekli ve büyüklüğünün işitmeyi etkilediğini göstermektedir.

4. Kemikçik zincirindeki yokluk ve 
ortalama işitme kaybı arasındaki ilişki de en fazla işitme kaybı oranı $36.6 \mathrm{~dB}$ ile total ossiküler yokluğun bulunduğu kolesteatomlu kronik otitlerdir. En az işitme kaybı oranı ise $26.3 \mathrm{~dB}$ ile ossiküler devamsızlığın bulunduğu, fakat stapesin tam olarak bulunduğu kolesteatomlu kronik otitler olarak bulunmuştur.

\section{Attik perforasyonu bulunan}

kulaklarda ortalama iletim tipi işitme kaybı oranı $31.6 \mathrm{~dB}$ olarak bulunmuştur. Attik perforasyonunda işitme kaybımn fazla olması bu tip perforasyonu olan kulaklarda sıklıkla kolesteatoma gelişmesi sonucu kemikçik zincirindeki kopukluğa bağlanabilir.

6. Subtotal perforasyonu bulunan ve timpanosklerozun bulunduğu olgularda iletim tipi işitme kaybı oranı $32.9 \mathrm{~dB}$ olarak bulunmuştur.

7. Kemik zincirin normal olduğu

olgularda ortalama işitme kaybı oranı 26.9 dB olarak saptanmıştır.

8. Tüm olgular arasında en fazla işitme kaybı oranı $37.5 \mathrm{~dB}$ olarak kemikçik zincirinin total kayıp ve zarın total perfore olduğu kolesteatomlu kronik otitli olgularda bulunmuştur.

En sık sensorinöral işitme kaybı miktarı 15-30 dB arası olguların \%38.3'ünde rastlanmıştır.

\section{KAYNAKLAR}

1. Akyıldız, A.N. : Kulak Hastalıkları ve Mikrocerrahisi. Ankara, Bilimsel Tıp Yayınevi, 1998, pp. 86,337,373.

2. Smyth GDL: Chronic otitis media. In Campbell EE (ed).English Otolaıyngology. Philadelphia, Harper-Row Co. 1985, vol I ch 19.

3. Austin DF :Sound Conduction of the Dieseased Ear .J.Laryngol.Otol 1978;92:367

4. Lerut B,Pfammatter A,Moons J,Linder T.Fonctional correlations of tympanic membrane perforation size. Otol Neurotol. 2012 ; 33(3): 379-86

5. Peek F.A.W, Huisman MA, Berckmans R.J, Sturk A,Van Loon J,Grate J.J Lipopolysaccharide Concentration and Bone Resorption in cholesteatoma. Otol Neurotol.2003; 24(5): 709-713

6. Thomsen J, Bretlau P, Balslev Joorgensen M. Bone resorption in chronic otitis media. The role of cholesteatoma, amust or an adjunt. Clin Otolaryngol 1981;6:179-86.

7. Kurihara A, Toshima M, Yuasa R, Takasaka T. Bone destruction mechanisms inchronic otitis media with cholesteatoma: specific
7. Kurihara A, Toshima M, Yuasa R, Takasaka $T$. Bone destruction mechanisms inchronic otitis media with cholesteatoma: specific production by cholesteatoma tissue in culture of bone-resorbing activity attributable to interleukin -1 alpha. Ann OtolRhinol Laryngol. 1991;100(12):989 -98.

8. Macri J. R, Chole R. A, Bone Erosion in Experimental Cholesteatoma- the Effect of implanted Barriers. Otolaryngology- Head and Neck Surgery 1985; 93 (1): 3-16

9. Avnstorp $M B$,Homoe P,Bjerregaard $P$,Jensen RG. Chronic suppurative otitis media,middle ear patholgy and corresponding hearing loss in a cohort of Greenlandic children.Int J Pediatr Otorhinolaryngol 2016; 83: 148-53.

10. Mayerhoff WL, Kim SC, Paparela MM: Pathology of Chronic Otitis Media. Ann Otol Rhinol Laıyngol 1978; 87: 749-759

11. Friedmann L: The Comparative Pathology of Otitis Media- Experimental and Human. 2: The Histopathology of Experimental Cholesteatoma. J. Layyngolog Otolog 1955; 69: 588-601 
12. Schucknecht Hf: Pathology of the ear. Cambridge, Mass, Harvard University Press, 1974, pp. 23-42.

13. Fridmann L: Epidermoid cholesteatoma and cholesterol granüloma, experimental and human. Ann Otol Rhinol Laiyngol 1959; 68: 57-79,

14. Paparella MM, Kim CS : Mastoidectomy update. Lalyngopscope 1977; 87: 1977-1988

15. Paparella MM: Quiet labyrinthine complicatoins from chronic otitis media. J Laryngol Otol 1983; (suppl 8) : 53-58,.

16. Jaisinghani VJ, Paparella MM, Schachem PA, Le CT:Tympanic membran/ middle ear pathologic correlates in chronic otitis media. Laryngoscope 1999; 109(5):712-6,

17. Jeng FC, Tsai MH, Brown CJ. Relationship of preoperative findings and ossicüler discontinuity in chronic otitis media.Otol Neurotol 2003; 24(1): 29-32

18. Mehta RP, Harris JP, Nadol JB. Malleus fixation: Clinical and histopatholjic findings..Ann Otol Rhinol Laryngol 2002; 111: 246-254

19. Sade J, Halevy A : The Aetiology of bone destruction in chronic otitis media. J Laıyngol and Otol 1974; .84: 139-143

20. Tos $M$ : Pathology of the ossiküler chain in various chronic middle ear diseases. J Laıyngol and Otol 1979; 93: 769-780

21. Bhaya MH, Schachern PA, Morizono T, Paparella MM Pathogenesis of tympanosclerosis. Otolaıyngol Head Neck Surg 1993;109 (3 Pt 1): 413-20

22. Nakajima $\mathrm{HH}$ Experimental and clinical studies of malleus fixation. Laryngoscope 2005; 115(1): 147-154 